Article

\title{
Surface Modification of Flax Yarns by Enzymatic Treatment and Their Interfacial Adhesion with Thermoset Matrices
}

\author{
Maria Carolina Seghini ${ }^{1, *}$, Jacopo Tirillò ${ }^{1, *}$, Maria Paola Bracciale ${ }^{1} \mathbb{D}$, Fabienne Touchard ${ }^{2}$, \\ Laurence Chocinski-Arnault ${ }^{2}$, Antonio Zuorro ${ }^{1}{ }^{1}$, Roberto Lavecchia ${ }^{1}$ and Fabrizio Sarasini ${ }^{1}$ (B) \\ 1 Department of Chemical Engineering Materials Environment, Sapienza-Università di Roma, \\ 00184 Roma, Italy; mariapaola.bracciale@uniroma1.it (M.P.B.); antonio.zuorro@uniroma1.it (A.Z.); \\ roberto.lavecchia@uniroma1.it (R.L.); fabrizio.sarasini@uniroma1.it (F.S.) \\ 2 Département Physique et Mécanique des Matériaux, ENSMA, Institut PPRIME, \\ CNRS-ENSMA-Université de Poitiers, 86961 Futuroscope CEDEX, France; \\ fabienne.touchard@ensma.fr (F.T.); laurence.chocinski@ensma.fr (L.C.-A.) \\ * Correspondence: mariacarolina.seghini@uniroma1.it (M.C.S.); jacopo.tirillo@uniroma1.it (J.T.); \\ Tel.: +39-0644585314 (M.C.S.); +39-0644885908 (J.T.)
}

Received: 4 April 2020; Accepted: 18 April 2020; Published: 23 April 2020

\begin{abstract}
The aim of this study was to assess the effects of commercially available and relatively inexpensive enzyme preparations based on endo 1,4- $\beta$-xylanase, pectinase and xyloglucanase on the thermal (TGA), morphological (SEM), chemical (FT-IR) and mechanical (single yarn tensile tests) properties of flax yarns. The preparation based on pectinase and xyloglucanase provided the best results, resulting in the effective removal of hydrophilic components such as hemicellulose and pectin, the individualization of yarns and increased thermal stability at the expense of a reduction in mechanical properties, depending on the treatment parameters. Single yarn fragmentation tests pointed out an improved interfacial adhesion after enzymatic treatment, with reduced debonding length values of $18 \%$ for an epoxy matrix and up to $36 \%$ for a vinylester resin compared to untreated flax yarns.
\end{abstract}

Keywords: flax fibres; enzymatic treatment; natural fibres; interface/interphase; surface modification treatments

\section{Introduction}

The development of high-performance natural fibre composites cannot neglect the optimization of the fibre/matrix interfacial adhesion [1]. The importance of the fibre/matrix interface for the macroscopic response of fibre-reinforced composites is well consolidated, and it is not an easy task to find an ideal interface able to optimize simultaneously all the macroscopic properties that are directly or indirectly affected by its characteristics, i.e., tensile strength, fracture toughness, resistance to creep, fatigue, dimensional stability and environmental degradation. This consideration leads to the full awareness that interfacial properties need to be optimized rather than maximized [2]. For these reasons, the improvement of the adhesion properties between natural fibres and polymer matrices can be based on the optimization of the chemistry of the sizing agents or on the surface modification of the fibres to increase the bonding and wettability of the matrix. In this regard, numerous strategies have been devised to address the limitations of natural fibres, mainly ascribed to their hydrophilic character that precludes a suitable interfacial adhesion with hydrophobic polymer matrices, but at the same time increases moisture absorption and related microbiological degradation [1]. In this field, the engineering of fibres' surfaces for their effective incorporation in composite materials with reduced costs and 
environmental impact represents a noticeable challenge. With this in mind, many strategies that have been investigated over the years suffer from the need to handle large amounts of chemicals [3-6] or complex equipment [7-11], which can limit their full industrial exploitation. Another recent approach consists of decorating the fibres' surface with nanostructures to increase the surface area and the stress transfer of the polymer matrix [12-14], but this strategy usually involves several processing steps that make it less attractive for industrial applications. In [15], the authors reported the grafting of $\mathrm{TiO}_{2}$ onto flax fibres with a view to increasing the mechanical properties of poly lactic acid-based composites. The fibre treatment needed two steps, namely dewaxing and oxidation. In this regard, fibres were first treated with boiling acetone and then $\mathrm{NaOH}$ that was later neutralized by using a diluted citric acid solution. In the second step, the hydroxyl groups of the flax fibres were oxidized to carboxylic groups by using TEMPO (2,2,6,6-Tetramethylpiperidine 1-oxyl) and then finally immersed in the sol for the synthesis of $\mathrm{TiO}_{2}$ based on titanium isopropoxide as a precursor. A slight increase in the interlaminar shear strength (ILSS) and in the thermal and moisture resistance of the resulting composites was achieved, but with a remarkable complexity.

An environmentally friendly substitute for chemical and physical strategies is based on biological agents such as fungi [16-18] and enzymes [19-21] or supercritical fluids [22,23]. These modifications give advantages over chemical and physical methods, including their selectivity, the lower energy input required and their recyclability and reusability. In particular, the use of enzymes for textile and natural fibre modification is swiftly growing. The enzymatic treatment represents a green way to modify natural fibres, and in literature enzymatic treatments have been used with two final aims: (i) the extraction of bast fibres from non-fibrous tissues in stems as an alternative to dew retting [24,25], and (ii) the surface modification of fibres already extracted in order to reduce hydrophilicity and increase thermal stability [21,26]. In these latter studies, the enzymatic treatment was reported to be able to remove undesirable substances like pectin, hemicelluloses, lignin and waxes from the surface of the fibres, improving fibre/matrix adhesion, moisture resistance and thermal stability. In fact, pectin and hemicellulose are the main sources of surface polarity, which promotes hydrophilic behaviour and leads to moisture absorption. An effective treatment requires an accurate choice of enzymes and their contents. The leading enzymes used in the fibre modification are pectinases, used to hydrolyse pectin; hemicellulases (xylanases), able to destroy the hemicellulosic material; laccases, able to degrade lignin; and cellulases, responsible for the degradation of $\beta-1,4$-glucosidic bonds in crystalline and amorphous cellulose [27]. In some studies, enzymes are combined with chelating agents, such as EDTA (ethylene diamine tetra-acetic acid) or EDTMPA (ethylene diamine tetra methylene phosphonic acid), whose role is to make pectin easily attacked by enzymes by extracting calcium ions from pectin in the cell walls of the plant $[28,29]$.

Different studies in literature have investigated the effect of enzymatic treatments on the mechanical behaviour of composite materials. Bledzki et al. [30] addressed the effects of an enzymatic treatment with fungamix on the properties of abaca fibres and their polypropylene-based composites. The enzymatic treatment caused a decrease in the fibre roughness and pronounced fibrillation, while the tensile and flexural tests highlighted an increase of $5 \%-45 \%$ for the tensile strength and of $10 \%-35 \%$ for the flexural strength after the fibre modification. Moreover, the moisture absorption of the composites was reduced by $20 \%-45 \%$. George et al. [20] tested different commercially available enzymes—namely xylanase, polygalacturonase, laccase and xylanase + cellulase-on hemp and flax fibres embedded in a polypropylene matrix. Among all treatments, the one based on polygalacturonase was the most effective in decreasing the amount of hemicellulose and pectin, thus providing composite materials with a better water resistance and thermal stability compared to the untreated ones while preserving their mechanical properties.

These available studies suggest that enzymatic treatments show potential to shape the interfacial adhesion in composites reinforced with natural fibres. In this framework, this study is one of the first that addresses the influence of commercially available and inexpensive enzyme preparations without the presence of any chemicals on the morphological, thermal and mechanical properties of flax yarns 
intended for composite applications. In addition, this study reports an assessment, by the single-fibre fragmentation test (SFFT), of the degree of fibre/matrix adhesion with epoxy and vinylester matrices.

\section{Materials and Methods}

\subsection{Raw Materials}

Flax (Linum usitatissimum) yarns were carefully removed by hand from a fabric with a $2 \times 2$ twill architecture and fibre area weight equal to $200 \mathrm{~g} / \mathrm{m}^{2}$ provided by Composites Evolution (Chesterfield, UK), which did not include any optimized sizing formulation. The thermoset matrices used to assess the interfacial adhesion with flax yarns were an epoxy system (Epoxy Prime 27 with a PRIME 20 slow hardener, mixing ratio 100:28) supplied by Gurit (Newport, UK) and a styrene-free vinylester (Advalite VH-1207) provided by Reichhold (London, UK), which was cured using a Norpol Peroxide PMEC N24 hardener with a mixing ratio of $1 \mathrm{phr}$.

\subsection{Biochemical Enzymatic Treatment}

In order to remove pectin and hemicellulose, flax fabrics and yarns were treated with commercial enzyme preparations of relatively low cost. Feedlyve AXC $1500 \mathrm{~L}$ and Peclyve EXG commercial enzyme solutions, supplied by Lyven SA (Colombelles, France), were selected. Feedlyve AXC $1500 \mathrm{~L}$ is rich in endo 1,4- $\beta$-xylanase, an enzyme that is able to degrade hemicellulose by attacking the xylan backbone of xylo-oligosaccharides [27]. Peclyve EXG is rich in pectinase and xyloglucanase, which can remove pectin and hemicellulose, respectively. The biochemical treatment was performed on both flax fabrics and flax yarns. Flax fabrics, with dimensions of $3 \times 3 \mathrm{~cm}^{2}$, and flax yarns, with lengths of $80 \mathrm{~mm}$, were treated in small borosilicate lab jars and placed into a thermostatic and magnetically stirred water bath at the temperature of $50{ }^{\circ} \mathrm{C}$. Different concentrations and times were selected (Table 1). Optimum enzyme-specific $\mathrm{pH}$ values were used. Afterwards, drying was performed at $80^{\circ} \mathrm{C}$ for $24 \mathrm{~h}$.

Table 1. Enzyme preparations and summary of all enzymatic treatment conditions.

\begin{tabular}{|c|c|c|c|c|c|c|}
\hline Enzyme Solution & Biological Source & Main Activities & $\begin{array}{l}\text { Enzyme Load } \\
\text { [wt \%] }\end{array}$ & Time [h] & $\begin{array}{c}\mathrm{T} \\
{\left[{ }^{\circ} \mathrm{C}\right]}\end{array}$ & $\mathrm{pH}$ \\
\hline Feedly & Trichoderma lon & & $0.5-2.5-5$ & $2-3$ & 50 & 5.5 \\
\hline Peclyve EXG & Aspergillus niger & Pectinase Xyloglucanase & $0.5-2.5-5-7.5-10$ & $2-3-4.5-6$ & 50 & 5 \\
\hline
\end{tabular}

\subsection{Characterization of Wetting Properties}

The wetting properties of the flax fabric were assessed by a water drop test, performed using an OCA 15 Pro equipment (DataPhysics GmbH, Filderstadt, Germany). Generally, this system is used in order to perform a contact angle measurement using the sessile drop method on homogeneous solid substrates. In this work, due to the non-homogeneous characteristics of flax fabrics, it was not possible to carry out a contact angle measurement, and the wetting behaviour of the fabric was measured in terms of time for the complete absorption of the liquid, i.e., water retention time. During the test, degassed water drops with a volume of $4 \mu \mathrm{L}$ were applied to the flax fabric and the time until the applied drop was absorbed completely was measured.

\subsection{Tensile Characterization of Flax Yarns}

Single yarn tensile tests on untreated and enzyme-modified flax yarns were carried out in accordance with ASTM C-1557 at room temperature with a Zwick/Roell Z010 machine (Ulm, Germany) equipped with a $1 \mathrm{kN}$ load cell. A cross-head speed of $2 \mathrm{~mm} / \mathrm{min}$ was used for the tests conducted in displacement control. The flax yarns were fixed using a glue (Loctite ${ }^{\mathrm{TM}}$ Gel Superglue, Milan, Italy) on card tabs with a central opening equal to the gauge length of $40 \mathrm{~mm}$. Prior to the test, 20-30 yarns for each treatment were conditioned at $45^{\circ} \mathrm{C}$ for $24 \mathrm{~h}$ for moisture removal, while their diameters were calculated by optical microscopy as the average of at least ten measurements along the gauge length. 


\subsection{Fourier Transform Infrared Spectroscopy Analysis (FT-IR)}

The surface modification of flax yarns caused by the enzymatic treatments was investigated by a Fourier-transform infrared (FT-IR) analysis, conducted with a Bruker Vertex 70 spectrometer (Bruker Optik GmbH, Ettlingen, Germany) equipped with a single reflection Diamond ATR cell, a standard MIR source (HeNe) and a room temperature DTGS detector. A spectral resolution of $3 \mathrm{~cm}^{-1}$ in the mid-infrared range $\left(400-4000 \mathrm{~cm}^{-1}\right)$ with 512 scans was adopted to record the spectra.

\subsection{Thermogravimetric Analysis (TGA)}

The thermal degradation of the untreated and modified flax yarns was analyzed by a thermogravimetric analysis. The tests were conducted with a SetSys Evolution (Setaram Instrumentation, Caluire, France) instrument, where samples were placed in an alumina pan and subjected to a heating rate of $10^{\circ} \mathrm{C} / \mathrm{min}$ in the range $25-800^{\circ} \mathrm{C}$ in a nitrogen atmosphere.

\subsection{Single Yarn Fragmentation Test}

The effect of enzymatic treatments on the quality of the yarn/matrix adhesion with epoxy and vinylester matrices was studied by adapting the well-known single fiber fragmentation test (SFFT) to the yarn scale, as already discussed in $[8,23,31]$. Details of the mould and of the procedure used to manufacture the single yarn composite specimens can be found in [23]. Prior to sample manufacturing, the flax yarns were conditioned at $45^{\circ} \mathrm{C}$ for $24 \mathrm{~h}$. The tests were carried out in an Instron E1000 ElectroPuls test machine (Norwood, MA, USA) equipped with a load cell of $2 \mathrm{kN}$ in displacement control (crosshead speed $=0.005 \mathrm{~mm} / \mathrm{min}$ ). At least ten diameter measurements by optical microscopy (Zeiss, Oberkochen, Germany) were used to provide an average value of the yarn diameter. Two end-test criteria were considered: the specimen's failure or achievement of the fragmentation saturation level, where no new yarn breaks occur after a subsequent strain increase of $0.5 \%$ [32]. The Kelly-Tyson model requires that the flax yarns show elongation at break values 2-3 times smaller than the matrix, a condition that was experimentally verified in the present study [33].

\subsection{X-Ray Microtomography}

Single yarn composite specimens were analyzed by an UltraTom CT scanner (RX Solutions, Chavanod, France) with a resolution of $1.5 \mu \mathrm{m}$, an accelerating voltage of $50 \mathrm{kV}$ and a beam current of $157 \mu \mathrm{A}$.

\subsection{Optical and FE-SEM Observations}

A ZEISS Axio Imager optical microscope (Oberkochen, Germany) was used to measure the flax yarn diameters and the fragment lengths. The morphology of the enzymatically modified and neat flax yarns was investigated by scanning electron microscopy (FE-SEM) with a Zeiss Auriga (Oberkochen, Germany). Before the SEM analysis, the specimens were coated with a thin layer of chromium by sputtering.

\section{Results and Discussion}

\subsection{Characterization of Flax Yarns After Enzymatic Treatment}

In the initial phase of the work, enzymatic treatments were carried out only on flax fabrics. For both Feedlyve and Peclyve preparations, the fabrics were treated using an enzyme load of 0.5, 2.5 and $5 \mathrm{wt} \%$ and a duration of 2,3 and $6 \mathrm{~h}$. The aim of this phase of the study was to verify the actual effect of the two enzymatic preparations on the surface properties of flax and thus to select the solution able to produce the best results. Enzymes are able to modify surface properties without significantly affecting bulk properties [34]. It was supposed that the removal of hemicellulose and pectin from the flax fibres would reduce their hydrophilic behaviour, making them more resistant to moisture and 
thermally stable. In this framework, the wetting properties of the untreated and treated flax fabrics were analysed by a water drop test. Representative values of the absorption times are reported in Table 2. Due to the presence of hydroxyl and strongly polar groups, the untreated flax fabrics showed a marked hydrophilic behaviour. Water retention times lower than $1 \mathrm{~s}$ were found for the as-received flax fabric. From the results reported in Table 2, it is possible to notice that flax fabrics displayed a wetting behaviour strongly dependent on the type of enzymatic preparation used. An increase in the hydrophobic behaviour was produced after the application of Peclyve. In contrast, the flax fabrics treated with Feedlyve maintained their strong hydrophilic behaviour.

Table 2. Water absorption time values obtained for the untreated and enzymatically treated flax fabric surface.

\begin{tabular}{ccccc}
\hline Flax Fabric & $\begin{array}{c}\text { Absorption } \\
\text { Time t [s] }\end{array}$ & $\begin{array}{c}\text { Absorption Time } \mathbf{t} \\
\text { after 2 h } \\
\text { Treatment [s] }\end{array}$ & $\begin{array}{c}\text { Absorption Time t } \\
\text { after 3 h } \\
\text { Treatment [s] }\end{array}$ & $\begin{array}{c}\text { Absorption Time } \mathbf{t} \\
\text { after } \mathbf{6 ~ h} \\
\text { Treatment [s] }\end{array}$ \\
\hline Neat & $\mathrm{T}<1$ & - & - & - \\
Peclyve $0.5 \mathrm{wt} \%$ & - & 1 & 1.2 & 5.5 \\
Peclyve $2.5 \mathrm{wt} \%$ & - & 1.4 & 2.2 & 1.5 \\
Peclyve $5 \mathrm{wt} \%$ & - & 1.5 & 35 & 50 \\
Feedlyve $0.5 \mathrm{wt} \%$ & - & $\mathrm{t}<2$ & $\mathrm{t}<1$ & 1 \\
Feedlyve $2.5 \mathrm{wt} \%$ & - & $\mathrm{t}<2$ & $\mathrm{t}<1$ & $\mathrm{t}<1$ \\
Feedlyve $5 \mathrm{wt} \%$ & - & 1 & & $\mathrm{t}<1$ \\
\hline
\end{tabular}

Figure 1 compares the time sequences of the water drop tests carried out for fabrics treated using Feedlyve and Peclyve at $5 \mathrm{wt} \%$ for a duration of $6 \mathrm{~h}$. A maximum value of water retention time of $50 \mathrm{~s}$ was obtained after the treatment with Peclyve. In contrast, the flax fabric treated by the Feedlyve showed a water retention time of lower than $1 \mathrm{~s}$. According to George et al. [21], the increase in hydrophobic behaviour may be explained by the removal of pectin and hemicellulose fractions on the fibres' surface produced by pectinase and xyloglucanase. The better results obtained by Peclyve can be attributed to the synergic action of pectinase and xyloglucanase. In contrast, the presence of only endo $1,4-\beta$-xylanase in Feedlyve was not able to induce substantial modifications of the flax properties.

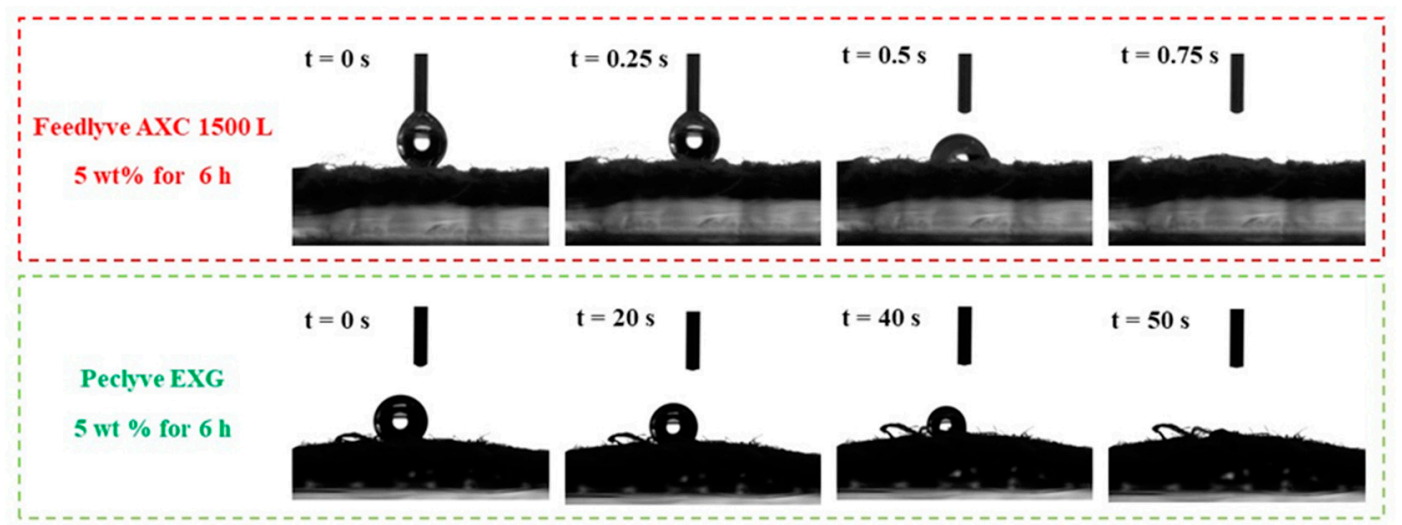

Figure 1. Representative time sequences of the water drop test performed on the flax fabrics treated with Feedlyve and Peclyve at $5 \mathrm{wt} \%$ for $6 \mathrm{~h}$.

De Prez et al. $[25,35]$ investigated different enzyme combinations based on several pectinase and hemicellulase activities, including up to three different enzymes applied to flax fibres, and discussed their effects on the chemical fibre composition, ease of fibre extraction and fibre fineness.

They identified some synergic combinations that resulted in enhanced cellulose content (polygalacturonase + xylanase), while combinations with three enzymes showed significant improvements in fibre fineness compared to the single enzyme treatments. It was hypothesized 
that when pectinases and hemicellulases are combined, the polymer network surrounding the fibre should be degraded more efficiently. In the present study, the removal of pectin and hemicellulose components resulted in a decrease in the surface polarity of the flax fabrics, reducing the presence of hydroxyl groups distributed on their surface. Based on these results, Peclyve was chosen as the most effective preparation to modify the surface properties of flax fibres. Therefore, the subsequent enzymatic treatments on flax yarns were performed using this preparation. To analyse in detail the action of the Peclyve solution, different solution concentrations $(2.5,5,7.5$ and $10 \mathrm{wt} \%)$ and treatment times $(3,4.5$ and $6 \mathrm{~h})$ were investigated. The water drop test, although useful for a qualitative analysis of the wetting behaviour of the different flax fabrics, was characterized by a large data dispersion, hence it proved to be inadequate in identifying a precise relationship between the process times and enzyme concentrations used.

The changes in the surface morphology of flax yarns produced by the Peclyve solution were compared with those of the untreated flax yarns. The differences between the surface morphology of neat and modified flax yarns using the Peclyve solution at $5 \mathrm{wt} \%$ for $6 \mathrm{~h}$ are reported in Figure 2 . One of the main effects observed after the enzymatic treatment was the removal of a substantial part of the impurities present on the untreated fibres—-such as fat and waxes-that bind the flax bundles together, ensuring good mechanical properties of the yarn [36].
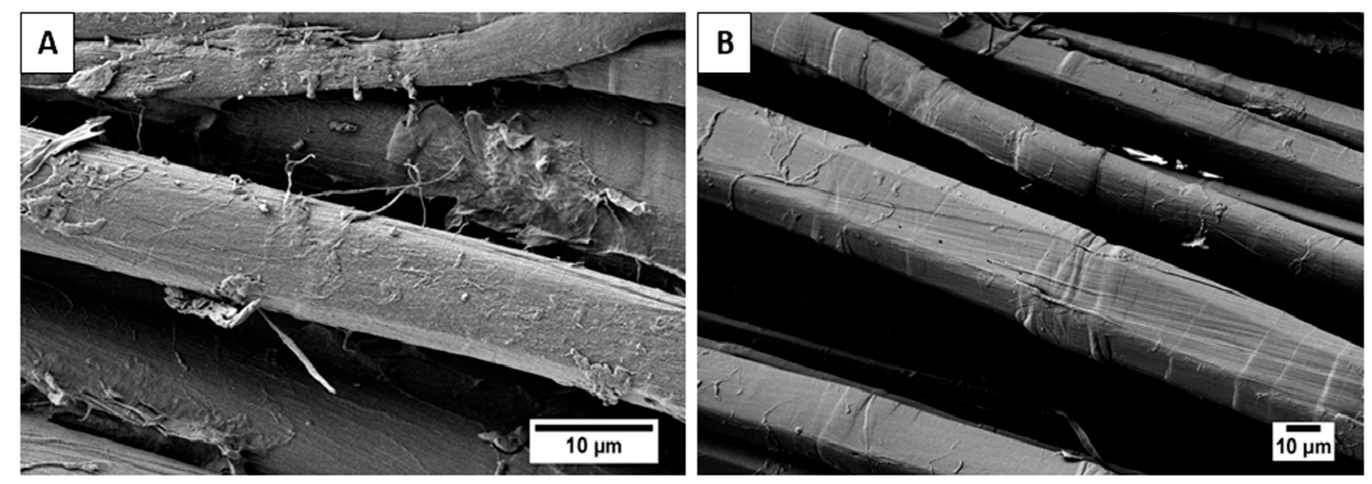

Figure 2. Comparison between the lateral surface of the untreated flax fibres (A) and the flax fibres treated with 5 wt \% Peclyve for $6 \mathrm{~h}(\mathbf{B})$.

The FE-SEM micrographs reported in Figure 3 show the morphologies of the flax yarns after the different enzymatic treatments. Irrespective of the treatment condition, flax yarn fibrillation and individualization were observed. It is worth highlighting that the longer the process time and the greater the enzyme concentration, the higher the fibrillation of yarns.

As reported by George et al. [21], pectinase is the enzyme that contributes the most to the separation of fibres from their yarn. An enzymatic effect observed only at high solution concentrations was the progressive breakage of the flax fibres present at the outer surface of the yarn. This effect was found for the yarns treated for $4.5 \mathrm{~h}$ and $6 \mathrm{~h}$ using a Peclyve concentration of $10 \mathrm{wt} \%$ (Figure 4).

The modification of the surface chemistry of flax yarns after the biochemical treatments was analyzed by Fourier-Transform Infrared (FT-IR) spectroscopy. To highlight the changes induced by the enzymatic treatment on the composition of the flax yarns, the FT-IR analysis was carried out on the samples treated using the minimum (Figure 5) and maximum (Figure 6) concentration of the Peclyve solution.

The spectra appear to be similar, however the main effect produced by the enzymatic treatment was a strong reduction in the bands at around $1736-1742 \mathrm{~cm}^{-1}$, which can be assigned to the carboxylic ester in the pectin and wax [37] and to the carbonyl C = O stretching of the acetyl groups of hemicellulose [38] and, at $1597 \mathrm{~cm}^{-1}, 1514 \mathrm{~cm}^{-1}$ and $1450 \mathrm{~cm}^{-1}$, of the lignin [8]. It is to be noted that the enzyme preparation used in the present study was not pure, therefore the presence of side enzyme activities cannot be excluded. The removal of pectin bonded to hemicellulose might have triggered the 
disruption of the network in line with the results in [21], where a reduction in the hemicellulose content in flax and hemp fibres was found after a treatment based only on pectinases (polygalacturonase and pectinmethylesterase). The reduction in the bands for hemicellulose, pectin and lignin was observed for flax yarns treated with both $2.5 \mathrm{wt} \%$ and $10 \mathrm{wt} \%$ Peclyve solution, thus confirming that the enzymatic treatment was able to successfully degrade hydrophilic substances like hemicellulose and pectin present on the surface of flax yarns.
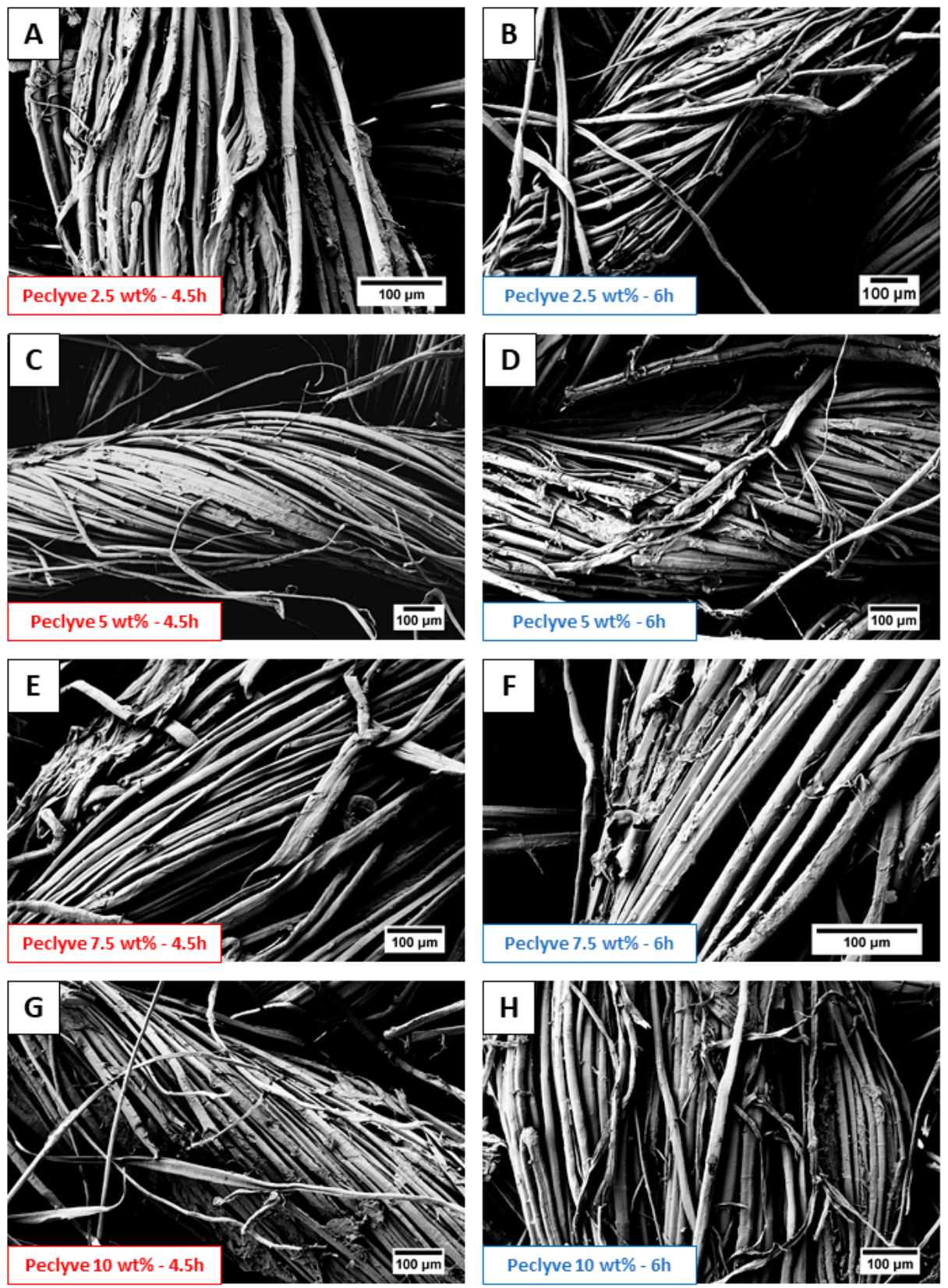

Figure 3. SEM micrographs of the flax yarns as a function of the different enzymatic treatments with Peclyve: (A) $2.5 \mathrm{wt} \%, 4.5 \mathrm{~h}$; (B) $2.5 \mathrm{wt} \%, 6 \mathrm{~h}$; (C) $5 \mathrm{wt} \%, 4.5 \mathrm{~h}$; (D) $5 \mathrm{wt} \%, 6 \mathrm{~h}$; (E) $7.5 \mathrm{wt} \%, 4.5 \mathrm{~h}$; (F) $7.5 \mathrm{wt} \%, 6 \mathrm{~h} ;(\mathrm{G}) 10 \mathrm{wt} \%, 4.5 \mathrm{~h} ;(\mathbf{H}) 10 \mathrm{wt} \%, 6 \mathrm{~h}$. 


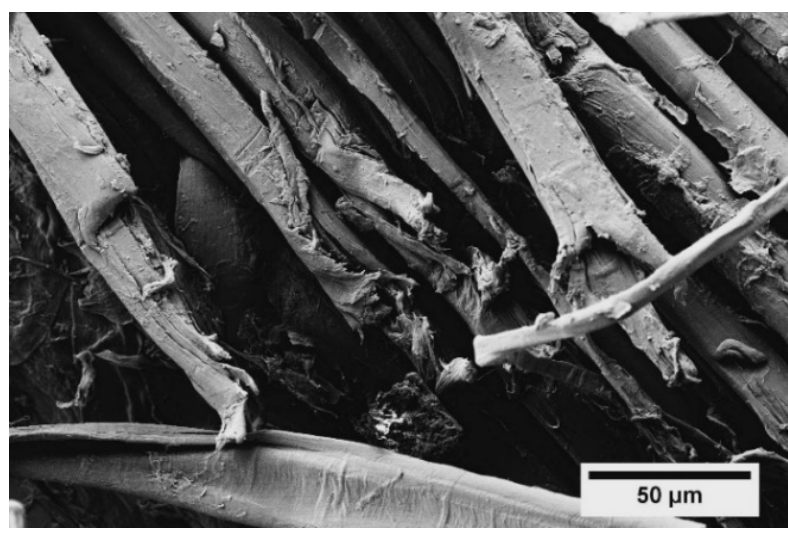

Figure 4. SEM micrograph of the flax yarn treated with $10 \mathrm{wt} \%$ Peclyve for $4.5 \mathrm{~h}$. The micrograph shows the damage to the outer fibres of the flax yarn after the enzymatic treatment.

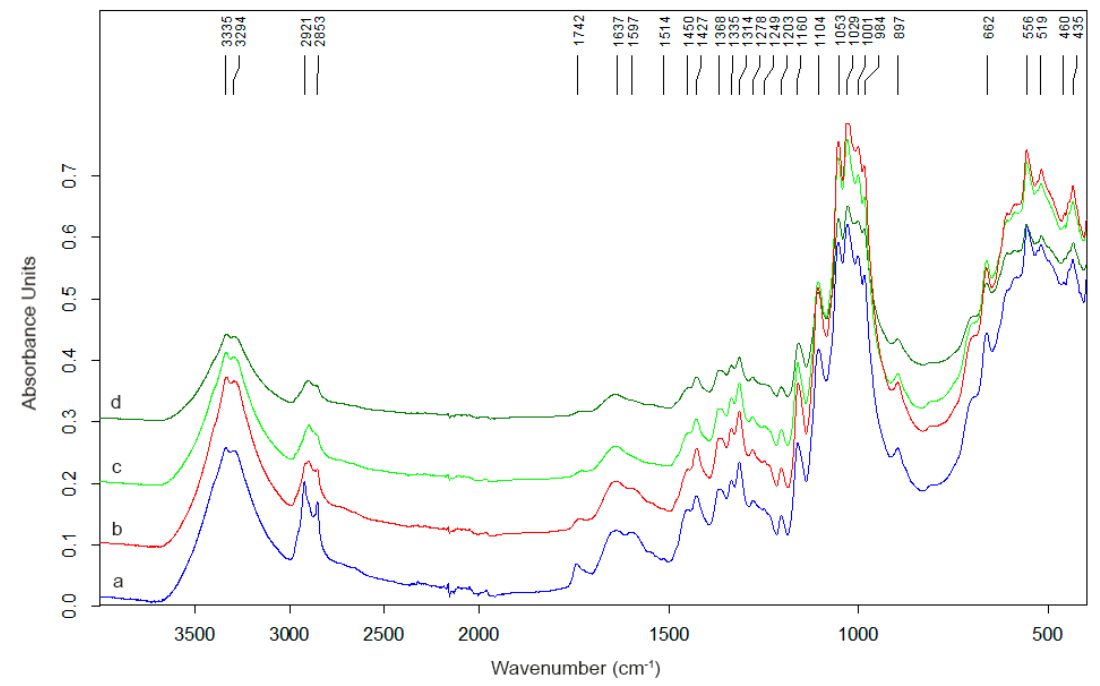

Figure 5. Infrared spectra of neat (a) and enzymatically modified flax yarns using $2.5 \mathrm{wt} \%$ Peclyve for $3 \mathrm{~h}(\mathbf{b}), 4.5 \mathrm{~h}(\mathbf{c})$ and $6 \mathrm{~h}(\mathrm{~d})$.

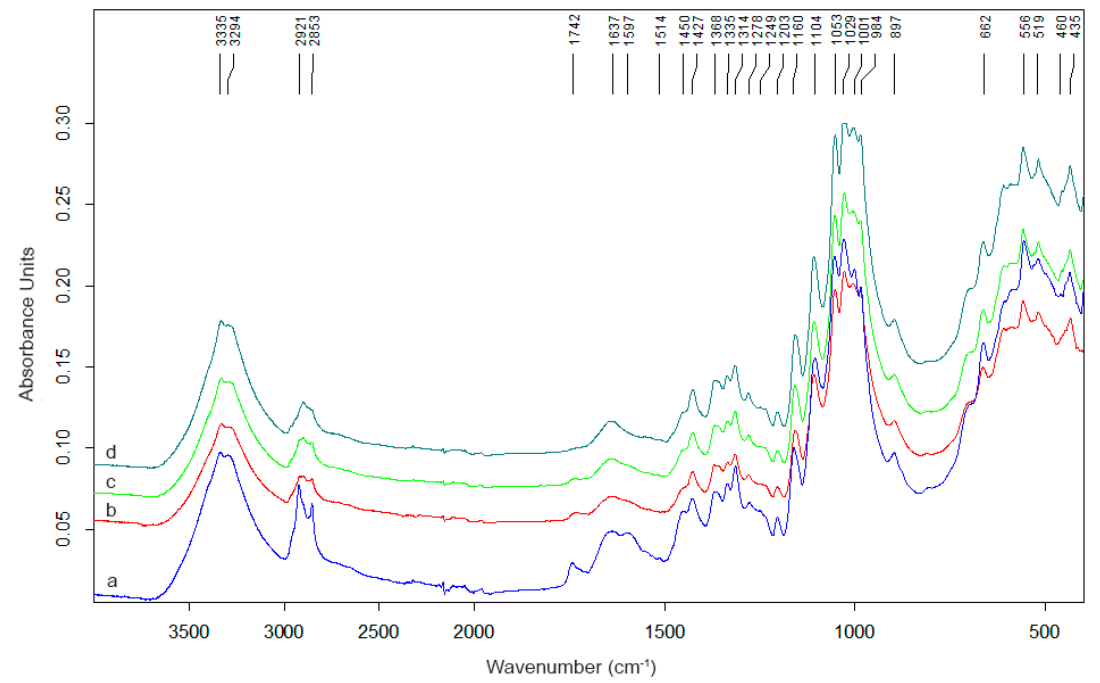

Figure 6. Infrared spectra of neat (a) and enzymatically modified flax yarns using $10 \mathrm{wt} \%$ Peclyve for $3 \mathrm{~h} \mathrm{(b),} 4.5 \mathrm{~h} \mathrm{(c)} \mathrm{and} 6 \mathrm{~h} \mathrm{(d).}$ 
Comparing the infrared spectra of the flax yarns enzymatically treated using a $2.5 \mathrm{wt} \%$ Peclyve solution for different durations (Figure 5), it is possible to notice that the longer the treatment time, the greater the removal efficiency of the enzymatic solution. The lowest hemicellulose and pectin bands were obtained after a treatment duration of $6 \mathrm{~h}$ (Figure $5 \mathrm{~d}$ ). These results are supported by the crystallinity index (CI) of cellulose, which was measured for the different flax yarns. Higher values of CI are associated with a greater amount of crystalline cellulose, thus confirming the ability of the enzymatic treatment to extract amorphous components $[39,40]$. In this work, a semiquantitative measurement of the CI of cellulose (Table 3 ) is presented, expressed as the intensity ratio between the IR absorption bands at 1427 and $897 \mathrm{~cm}^{-1}\left(\mathrm{I}_{1427} / \mathrm{I}_{897}\right)$, which belong to the $\mathrm{CH}_{2}$ bending mode of cellulose and to the $\mathrm{CH}$ in $\beta$-glycosidic linkages between monosaccharides [41].

Table 3. The crystallinity index of cellulose for the neat and enzymatically modified flax yarns using different times and Peclyve loads.

\begin{tabular}{ccc}
\hline Flax Yarn & Treatment Time & Cellulose Crystallinity index (CI) \\
\hline Neat & - & 1.01 \\
Peclyve $2.5 \mathrm{wt} \%$ & $3 \mathrm{~h}$ & 1 \\
Peclyve $2.5 \mathrm{wt} \%$ & $4.5 \mathrm{~h}$ & 1.15 \\
Peclyve $2.5 \mathrm{wt} \%$ & $6 \mathrm{~h}$ & 1.24 \\
Peclyve $10 \mathrm{wt} \%$ & $3 \mathrm{~h}$ & 1.36 \\
Peclyve $10 \mathrm{wt} \%$ & $4.5 \mathrm{~h}$ & 1.54 \\
Peclyve $10 \mathrm{wt} \%$ & $6 \mathrm{~h}$ & 1.54 \\
\hline
\end{tabular}

A progressive increase in the cellulose crystallinity index values was observed passing from the $3 \mathrm{~h}$ to the $6 \mathrm{~h}$ treatment. Concerning the infrared spectra of the flax yarns modified using a $10 \mathrm{wt} \%$ Peclyve solution (Figure 6), an additional reduction in the hemicellulose and lignin bands occurred. Negligible differences could be found between the infrared spectra of the flax yarns treated for $4.5 \mathrm{~h}$ and $6 \mathrm{~h}$, and the same cellulose CI value was measured. These results highlight that the use of the Peclyve solution with a concentration of $10 \mathrm{wt} \%$ allowed the maximum efficiency to be obtained after $4.5 \mathrm{~h}$ of treatment. No further removal of amorphous components from the surfaces of the flax fibres was produced using longer treatment times. Li and Pickering [29] reported the same trend in hemp fibres treated with combinations of pectinase and laccase with and without the presence of a chelator (ethylenediamine tetra(methylene phosphonic acid), EDTMPA). With a progressive removal of amorphous non-cellulosic compounds, the authors found a significant increase in the crystallinity index evaluated by the Segal method after enzymatic treatment, which passed from $66.3 \%$ to $86.3 \%$ for the raw and treated hemp fibres, respectively.

Figure 7 displays the representative thermographs, expressed as the mass loss and derivative mass loss for the neat and enzymatically treated flax yarns.

The neat flax yarns were characterized by the well-known three stages of degradation that depend on the different thermal stabilities of their constituents, i.e., cellulose, hemicellulose and lignin. While the first mass loss in the range of $60-120^{\circ} \mathrm{C}$ is due to the absorbed water, the additional two peaks at about $240-280^{\circ} \mathrm{C}$ and $340-360^{\circ} \mathrm{C}$ are ascribed to the degradation of pectin and hemicellulose and to cellulose, respectively [42,43]. Hemicellulose and pectin in lignocellulosic fibres decompose at a lower temperature than cellulose and lignin [21], therefore it can be assumed that the removal of the less thermally stable hemicellulose and pectin by enzymatic treatment, as confirmed by the FT-IR measurements, would improve the thermal resistance of the treated flax yarns. After the enzymatic treatment, a change in the thermal stability of the flax yarns occurred. The thermogravimetric analysis proved the enzymatic removal of hemicellulose and pectin components from the flax surface. In particular, the thermal stability of the flax yarns treated using the maximum concentration of $10 \mathrm{wt} \%$ of Peclyve was investigated. The thermograms reported in Figure 7 show that the peak related to water loss remained unchanged. However, the second step of the thermal degradation changed. In fact, contrary to the as-received flax, both the yarns treated for $4.5 \mathrm{~h}$ and $6 \mathrm{~h}$ did not show any step 
of weight loss associated with hemicellulose and the pectin decomposition. From the mass loss vs. temperature curves, it can be also seen that the onset degradation temperatures tended to increase after the enzymatic treatment compared with the untreated flax yarns, again confirming the removal of thermally liable constituents [29].
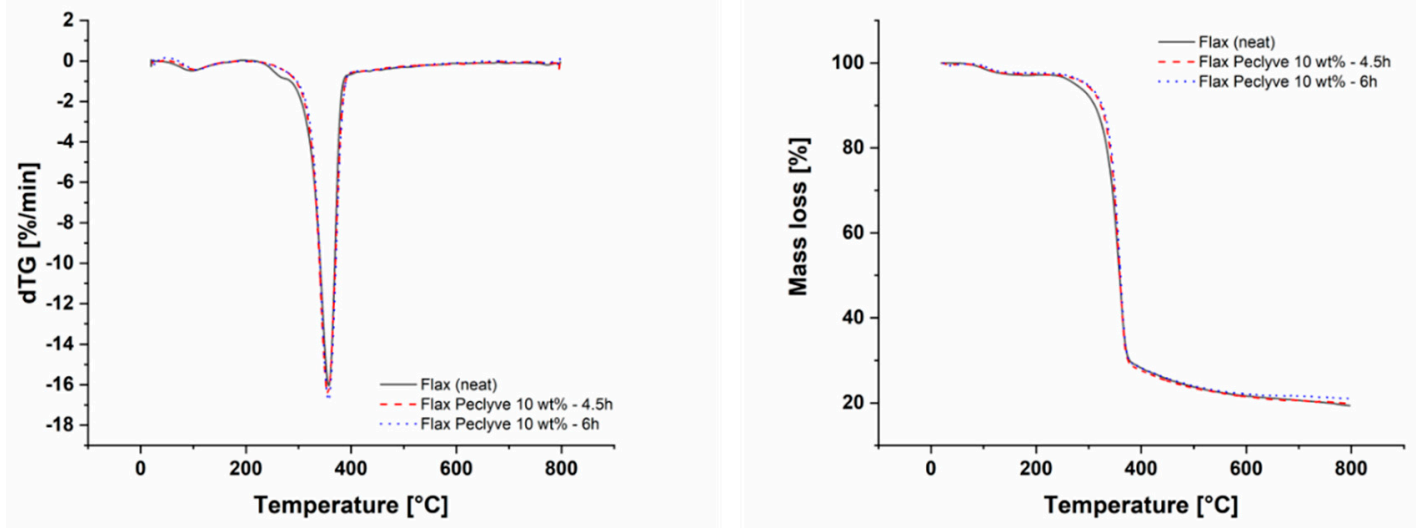

Figure 7. Derivative thermogravimetry (dTG) curves and thermogravimetric analysis (TGA) thermograms of flax yarns before and after enzymatic treatment.

Table 4 summarizes the maximum degradation temperature and the temperature of $10 \%$ weight loss for the untreated and the treated flax yarns. The enzymatically treated flax yarns displayed a maximum degradation temperature only slightly lower compared to that of the untreated ones, despite the removal of components that could result in a weaker macrostructure because of the disorder in bonding within the network [44]. An increase in the $10 \%$ weight loss temperature was obtained after both enzymatic treatments. In particular, the highest temperature value $\left(325.5^{\circ} \mathrm{C}\right)$ was obtained for the flax yarn after a $6 \mathrm{~h}$ treatment.

Table 4. Results of the thermogravimetric analysis for the different types of flax yarns.

\begin{tabular}{ccc}
\hline & $\begin{array}{c}\text { Maximum Degradation } \\
\text { Temperature }\left[{ }^{\circ} \mathrm{C}\right]\end{array}$ & $\begin{array}{c}\text { Temperature of 10\% } \\
\text { Weight Loss }\left[{ }^{\circ} \mathbf{C}\right]\end{array}$ \\
\hline Flax yarn (neat) & 357.2 & 311.3 \\
Peclyve 10 wt \%-4.5 $\mathrm{h}$ & 355.7 & 322.8 \\
Peclyve 10 wt \%-6 $\mathrm{h}$ & 356.7 & 325.5 \\
\hline
\end{tabular}

It was not possible to detect by thermogravimetric analysis any significant effect related to the lignin removal. Lignin decomposes slower and over a broader temperature range $\left(200-500{ }^{\circ} \mathrm{C}\right)$ compared to cellulose and the hemicellulose [45]. Flax fibres are usually characterized by a low amount of lignin, which is kept low because it enables an easier extraction of the fibres from the stem [1]. Therefore, even the untreated flax fibres did not display a marked degradation peak for the lignin in the $400-500{ }^{\circ} \mathrm{C}$ temperature range.

The mechanical properties of neat and enzymatically treated flax yarns were addressed by a single yarn tensile test and the results were statistically analyzed using the Weibull distribution (Equation (1)):

$$
\operatorname{Pr}(\sigma)=1-\exp \left[-\left(\frac{\sigma}{\sigma_{0}}\right)^{m}\right]
$$

where $\operatorname{Pr}(\sigma)$ represents the cumulative probability of failure as a function of applied stress $\sigma, m$ is the Weibull modulus and $\sigma_{0}$ is the characteristic strength. The failure probability $\left(P_{f}\right)$ was estimated in accordance with Equation (2):

$$
P_{f}=\frac{i-0.5}{N}
$$


where $N$ is the number of filaments tested and $i$ is the rank of the data point for each filament.

As shown in Table 5, the tensile strength and failure strain decreased after enzymatic treatments, in line with other studies on hemp fibres $[26,29]$. The reduction in mechanical performance can be linked with the enzymatic effect of yarn fibrillation observed by the FE-SEM analysis. A marked loss of tensile strength of about $58.5 \%$ was obtained after a treatment with the $10 \mathrm{wt} \%$ Peclyve solution for $6 \mathrm{~h}$. This tensile strength drop can be connected to the progressive breakage of the fibres present at the outer surface of the yarn produced at a high solution concentration (Figure 4). Another phenomenon able to explain the reduction in the mechanical performance of the yarns is likely to be the enzymatic removal of non-cellulosic constituents of flax, such as pectin, hemicellulose and lignin. Although they are not structural constituents of the fibre like cellulose, the non-cellulosic components have to keep the cellulose microfibrils linked together. A similar result was found by Liu et al. [26]. A reduction in the tensile properties of hemp fibres was reported after an enzymatic treatment with polygalacturonase. The authors proposed a "composite model" to explain the mechanical behaviour of plant fibres and the effect of the enzymatic preparation on their properties. The hemp fibre can be assimilated to a composite material, in which the cellulose microfibrils are the reinforcing fibres and the non-cellulosic components are the matrix. According to this model, the mechanical behaviour of the composite is controlled not only by the cellulose microfibrils but also by their adhesion with the non-cellulosic matrix.

Table 5. Tensile properties of neat and enzymatically modified flax yarns. The table shows also the relevant parameters of the Weibull distribution for the tensile strength.

\begin{tabular}{ccccccc}
\hline Flax Yarn & $\begin{array}{c}\mathbf{F}_{\max } \\
{[\mathbf{N}]}\end{array}$ & $\begin{array}{c}\text { Diameter } \\
{[\boldsymbol{\mu \mathrm { m } ]}}\end{array}$ & $\begin{array}{c}\boldsymbol{\sigma}_{\mathbf{f}} \\
{[\mathbf{M P a}]}\end{array}$ & $\begin{array}{c}\varepsilon_{\mathbf{f}} \\
{[\%]}\end{array}$ & $\begin{array}{c}\text { Characteristic } \\
\text { Strength } \boldsymbol{\sigma}_{\mathbf{0}}[\mathbf{M P a}]\end{array}$ & $\begin{array}{c}\text { Weibull } \\
\text { Modulus } \boldsymbol{m}\end{array}$ \\
\hline Neat & $19.8 \pm 4.8$ & $327 \pm 95$ & $236 \pm 57$ & $3.4 \pm 0.42$ & 257.4 & 5 \\
Peclyve 2.5 wt \%-4.5 h & $20.2 \pm 3.5$ & $376 \pm 69$ & $181 \pm 31$ & $3.55 \pm 0.49$ & 194 & 6.8 \\
Peclyve 5 wt \%-4.5 h & $16.9 \pm 3.6$ & $353 \pm 59$ & $172 \pm 36$ & $2.99 \pm 0.47$ & 186 & 5.5 \\
Peclyve 7.5 wt \%-4.5 h & $16.2 \pm 4$ & $348 \pm 77$ & $170 \pm 41$ & $2.95 \pm 0.41$ & 186 & 4.8 \\
Peclyve 10 wt \%-4.5 h & $14.8 \pm 3.5$ & $390 \pm 78$ & $123 \pm 29$ & $3.04 \pm 0.47$ & 134 & 4.6 \\
Peclyve 2.5 wt \%-6 h & $14.1 \pm 3.4$ & $382 \pm 61$ & $123 \pm 29$ & $3.03 \pm 0.59$ & 134 & 7.6 \\
Peclyve 5 wt \%-6 h & $13.7 \pm 2.1$ & $379 \pm 63$ & $121 \pm 19$ & $3.19 \pm 0.55$ & 129 & 3.5 \\
Peclyve 7.5 wt \%-6 h & $11.7 \pm 3.6$ & $370 \pm 74$ & $108 \pm 33$ & $2.93 \pm 0.6$ & 120 & 4.3 \\
Peclyve 10 wt \%-6 h & $11.1 \pm 2.8$ & $362 \pm 63$ & $107 \pm 27$ & $3.02 \pm 0.54$ & 118 & \\
\hline
\end{tabular}

The enzymatic degradation of the non-cellulosic matrix produced during the treatment resulted in a reduction in the fibre/matrix interface strength and in an overall decrease in the tensile properties of the fibres. Similar conclusions have been found for pectinase-treated hemp fibres by Saleem et al. [46]. In addition, lignin is a structural component and its degradation can result in a decrease in fibre tensile strength. The removal of amorphous non-cellulosic components from flax fibres has been confirmed by both FT-IR and thermogravimetric analysis. Several studies in literature investigated the dependence of tensile properties on the cellulose crystallinity index for plant fibres $[47,48]$. In general, an increase in tensile strength and Young's modulus with the increased crystallinity index was reported. As described previously, in this study an increase in the cellulose crystallinity index was observed after the different enzymatic treatments. The reduction in the tensile strength of enzymatically treated flax yarns can be related to an excessive degradation of the structural components of fibre, such as lignin. A similar behaviour was found by Mwaikambo et al. [49] for sisal fibres subjected to a mercerization treatment. The tensile strength and Young's modulus of sisal fibres were found to decrease with an increasing crystallinity index, a behaviour ascribed to the alkali treatment severity that resulted in a severe degradation of the fibres. The results of the single yarn tensile tests were analysed using the Weibull distribution (Table 5) and the corresponding curves are reported in Figure 8. Both the untreated and enzymatically treated flax yarns displayed a quasi-linear trend, pointing out that the final failure was controlled by a unique population of defects and that the treatment had an influence on the concentration and severity of the flaws but not on their nature. 

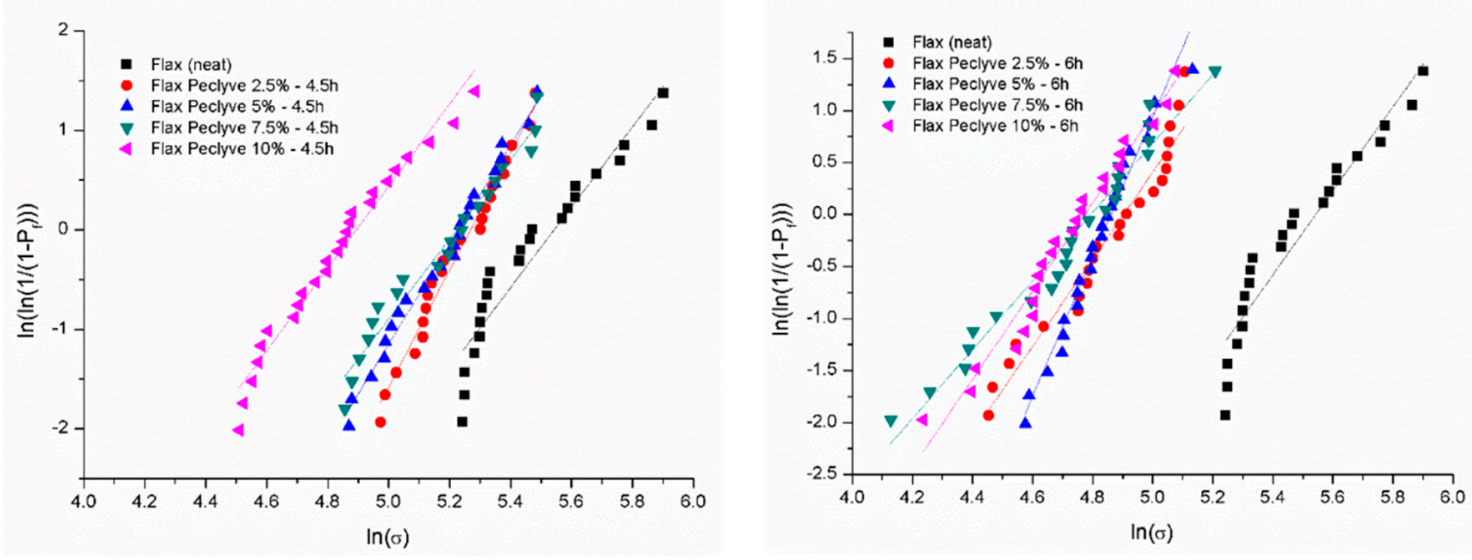

Figure 8. Weibull distribution plots of strength measured for neat flax yarns and enzymatically modified flax yarns for a duration of $4.5 \mathrm{~h}$ and $6 \mathrm{~h}$.

\subsection{Fibre/Matrix Interfacial Assessment by Single Yarn Fragmentation Test}

The interfacial adhesion analysis focused on two specific treatment conditions. In fact, according to the wetting test results and tensile strength values, single yarn fragmentation tests were performed on flax yarns treated using $5 \mathrm{wt} \%$ and $10 \mathrm{wt} \%$ Peclyve enzymatic preparation for $4.5 \mathrm{~h}$ and $6 \mathrm{~h}$. The $5 \mathrm{wt} \%, 4.5 \mathrm{~h}$ condition was selected because it allowed changes in the wetting properties of the flax yarns without significantly affecting their mechanical performance. Indeed, this enzymatic treatment condition produced a decrease in the tensile strength of the yarns of approximately $27 \%$. On the other hand, the condition of $10 \mathrm{wt} \%$ for $6 \mathrm{~h}$ was selected in order to assess the effects of the maximum concentration of Peclyve solution and of the maximum treatment duration on the adhesion quality between the flax yarns and thermoset matrices. At least 10 fragmentation tests were carried out for each family of single yarn composites. The experimental procedure has been thoroughly described in previous publications $[8,23,31]$. A comparison between the critical filament lengths measured for the untreated and the enzymatically treated single yarn composites is shown in Table 6.

Table 6. Critical fragment length and debonding length values for the different single yarn composites.

\begin{tabular}{cccc}
\hline Matrix & Flax Yarn & $\mathbf{1}_{\mathbf{c}}[\boldsymbol{\mu m}]$ & $\mathbf{1}_{\text {debonding }}[\boldsymbol{\mu m}]$ \\
\hline \multirow{4}{*}{ Epoxy } & Neat & $2687 \pm 631$ & $444 \pm 49$ \\
& Peclyve 5 wt \%-4.5 h & $2628 \pm 531$ & $353 \pm 89$ \\
& Peclyve 10 wt \%-6 h & $2511 \pm 203$ & $365 \pm 46$ \\
\multirow{3}{*}{ Vinylester } & Neat & $3942 \pm 807$ & $830 \pm 343$ \\
& Peclyve 5 wt \%-4.5 h & $3962 \pm 243$ & $628 \pm 128$ \\
& Peclyve 10 wt \%-6 h & $3554 \pm 776$ & $529 \pm 65$ \\
\hline
\end{tabular}

The results highlight that following the enzymatic treatments, a modest reduction in the critical yarn length in both epoxy and vinylester matrices occurred. In particular, the best adhesion quality was obtained after the treatment performed using the maximum concentration value of $10 \mathrm{wt} \%$ and the maximum treatment duration of $6 \mathrm{~h}$. In contrast, the flax/epoxy and the flax/vinylester systems where the flax yarn was treated using $5 \mathrm{wt} \%$ Peclyve solution for $4.5 \mathrm{~h}$ showed a critical yarn length almost equal to that obtained for the untreated single yarn composites. Unfortunately, the yarn critical length cannot be used as the exclusive parameter for evaluating the interfacial adhesion, as it strictly depends on the yarn strength that has been affected by the biochemical treatment [50]. Nevertheless, a comparison between the two matrix systems is possible, and the results suggest that flax/vinylester samples are characterized by larger values of critical lengths than the flax/epoxy ones. As already described for alternative flax yarn treatments $[8,23,31]$, this behaviour is related to the significant 
incompatibly between the highly hydrophilic flax yarns and the fully dispersive vinylester resin used in the present study.

Another parameter usually reported in interfacial studies is the interfacial shear strength (IFSS), which was calculated in accordance with the Kelly and Tyson model [33]. The strength value at the gauge length was obtained through the extrapolation of the Weibull cumulative distribution function [31], and the corresponding values are summarized in Table 7. By comparing the results found after the enzymatic treatment with those obtained for the as-received flax yarns, it is possible to highlight that a reduction in the IFSS values was produced after both surface modification treatments. This is especially true for the flax yarns enzymatically treated using $10 \mathrm{wt} \%$ Peclyve for $6 \mathrm{~h}$. A poor interfacial adhesion between the treated flax yarns and both the epoxy and vinylester matrices could be inferred from these results. However, as highlighted previously for the critical yarn length values, it is important to emphasize that the IFSS results are affected by the change in mechanical properties of flax yarns caused by the biochemical treatments. After the $10 \mathrm{wt} \%$ Peclyve $6 \mathrm{~h}$ treatment, the tensile strength at a length equal to the critical yarn length was reduced by $50 \%$, resulting in a strong decrease in the interfacial shear strength value with the epoxy and vinylester resin. The main problem with this kind of test for yarns is related to the correct measurement of the cross-sectional area of the yarn. In fact, a yarn includes voids among the technical fibres that are replaced by the matrix during the impregnation stage. This suggests that the IFSS values in the present work can only be used for a qualitative screening of the different flax yarns.

Table 7. Strength values at critical fragment length and interfacial shear strength (IFSS) values for the neat and enzymatically modified flax/epoxy and flax/vinylester systems.

\begin{tabular}{cccc}
\hline Matrix & Flax Yarn & $\left.\boldsymbol{\sigma}_{\mathbf{f}} \mathbf{l}_{\mathbf{c}}\right)[\mathbf{M P a}]$ & IFSS [MPa] \\
\hline \multirow{4}{*}{ Epoxy } & Neat & $406 \pm 18$ & $19.3 \pm 3.7$ \\
& Peclyve $5 \mathrm{wt} \%, 4.5 \mathrm{~h}$ & $283 \pm 10$ & $18.1 \pm 2.7$ \\
& Peclyve $10 \mathrm{wt} \%, 6 \mathrm{~h}$ & $203 \pm 3$ & $12.2 \pm 1.1$ \\
\multirow{2}{*}{ Vinylester } & Neat & $376 \pm 15$ & $13.9 \pm 2.8$ \\
& Peclyve $5 \mathrm{wt} \%, 4.5 \mathrm{~h}$ & $262 \pm 2$ & $10.5 \pm 1.4$ \\
& Peclyve $10 \mathrm{wt} \%, 6 \mathrm{~h}$ & $188 \pm 9$ & $7.8 \pm 2$ \\
\hline
\end{tabular}

Nevertheless, once again the better compatibility of the flax yarns with the epoxy matrix can be confirmed. A more reliable assessment of the level of interfacial adhesion can be based on another parameter, i.e., the debonding length [51]. An extended debonding zone is typical for weak interfacial bonds. In addition, this parameter does not depend on the constraints that are required to be satisfied for a sound single fibre fragmentation test (SFFT). Values included in Table 6 show reduced debonding lengths for the enzymatically treated yarns compared to the untreated ones, thus fostering a better interfacial adhesion of flax yarns with the epoxy and the vinylester matrices. The decrease in debonding length found for the enzymatically treated flax yarn with both epoxy and vinylester matrices can be linked to the increase in hydrophobic behaviour produced by the Peclyve enzymatic solution and a better fibre individualization that could promote the wettability of the resin. Similar debonding length values were measured for both the $5 \mathrm{wt} \% / 4.5 \mathrm{~h}$ and $10 \mathrm{wt} \% / 6 \mathrm{~h}$ treatment conditions. A decrease in the debonding length of about $18 \%$ was found for both enzymatically treated flax yarns in the epoxy-based composites. This result indicates that the different solution concentrations and treatment durations used affect the adhesion quality between the flax yarn and the epoxy matrix in the same way. The results found for the flax yarn/vinylester system are different. In this case, the enzymatic treatment performed with $10 \mathrm{wt} \%$ Peclyve for $6 \mathrm{~h}$ produced better adhesion results than the treatment with $5 \mathrm{wt} \%$ Peclyve for $4.5 \mathrm{~h}$. If compared with the as-received flax yarn/vinylester system, a decrease in the debonding length of about $36 \%$ was found for the Peclyve $10 \mathrm{wt} \% / 6 \mathrm{~h}$ flax yarn/vinylester composite.

The improved interfacial adhesion can be also inferred from micro-CT micrographs. This analysis was carried out only for the best performing treatment, i.e., the Peclyve $10 \mathrm{wt} \% / 6 \mathrm{~h}$ (Figure 9). 

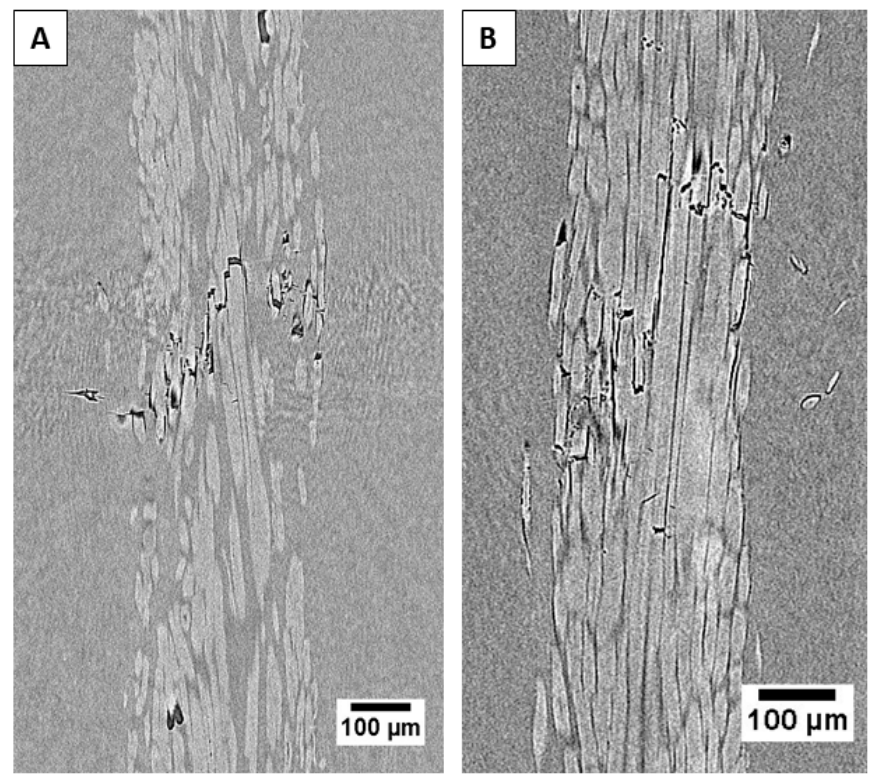

Figure 9. Representative debonding length observation by micro computed tomography. High resolution micro-CT images for the Peclyve $10 \mathrm{wt} \% / 6 \mathrm{~h}$ treated flax/epoxy (A) and flax/vinylester (B) single yarn samples.

From the micrographs, it is possible to observe the reduced debonding length in both systems, where the failure is mostly inside the flax yarn without evidence of extensive debonding, compared to the untreated case [31].

\section{Conclusions}

This study demonstrated that commercially available and inexpensive enzyme preparations containing pectinase and xyloglucanase have a synergistic effect in removing the hydrophilic pectic and hemicellulosic materials from flax yarns, which was confirmed by FT-IR and TGA analyses. From a microstructural point of view, the biochemical treatment resulted in a cleaning effect on the fiber surface, with an increase in thermal stability and a reduction in mechanical properties depending on the enzyme concentration and treatment duration. By taking advantage of the reduced hydrophilic behaviour and increased individualization of flax yarns, an improvement in the fibre/matrix compatibility with epoxy and vinylester matrices was obtained. After exposure to enzymatic treatments, single yarn fragmentation tests highlighted smaller debonding and critical yarn length values, especially with the fully dispersive vinylester matrix. Enzymes, being relatively inexpensive, recyclable and less energy intensive, represent a green and promising surface-modifying agent for natural fibres intended for composite applications.

Author Contributions: Conceptualization, F.S., F.T., and L.C.-A.; methodology, F.S., A.Z., R.L. and F.T.; validation, F.S., J.T., and M.C.S.; formal analysis, M.C.S.; investigation, M.C.S. and M.P.B.; data curation, M.C.S., L.C.-A., and J.T.; writing-original draft preparation, M.C.S., J.T. and F.S.; writing-review and editing, M.P.B., A.Z., R.L., F.T. and L.C.-A.; visualization, M.C.S.; supervision, F.S., J.T., and F.T. All authors have read and agreed to the published version of the manuscript.

Funding: This research received no external funding.

Conflicts of Interest: The authors declare no conflict of interest. 


\section{References}

1. Bourmaud, A.; Beaugrand, J.; Shah, D.U.; Placet, V.; Baley, C. Towards the design of high-performance plant fibre composites. Prog. Mater. Sci. 2018, 97, 347-408. [CrossRef]

2. Karger-Kocsis, J.; Mahmood, H.; Pegoretti, A. Recent advances in fiber/matrix interphase engineering for polymer composites. Prog. Mater. Sci. 2015, 73, 1-43. [CrossRef]

3. Bledzki, A.; Mamun, A.; Lucka-Gabor, M.; Gutowski, V. The effects of acetylation on properties of flax fibre and its polypropylene composites. Express Polym. Lett. 2008, 2, 413-422. [CrossRef]

4. Huo, S.; Thapa, A.; Ulven, C.A. Effect of surface treatments on interfacial properties of flax fiber-reinforced composites. Adv. Compos. Mater. 2013, 22, 109-121. [CrossRef]

5. Amiri, A.; Ulven, C.; Huo, S. Effect of chemical treatment of flax fiber and resin manipulation on service life of their composites using time-temperature superposition. Polymers 2015, 7, 1965-1978. [CrossRef]

6. Tserki, V.; Zafeiropoulos, N.E.; Simon, F.; Panayiotou, C. A study of the effect of acetylation and propionylation surface treatments on natural fibres. Compos. Part A Appl. Sci. Manuf. 2005, 36, 1110-1118. [CrossRef]

7. Bozaci, E.; Sever, K.; Sarikanat, M.; Seki, Y.; Demir, A.; Ozdogan, E.; Tavman, I. Effects of the atmospheric plasma treatments on surface and mechanical properties of flax fiber and adhesion between fiber-matrix for composite materials. Compos. Part B Eng. 2013, 45, 565-572. [CrossRef]

8. Seghini, M.C.; Touchard, F.; Sarasini, F.; Chocinski-Arnault, L.; Tirillò, J.; Bracciale, M.P.; Zvonek, M.; Cech, V. Effects of oxygen and tetravinylsilane plasma treatments on mechanical and interfacial properties of flax yarns in thermoset matrix composites. Cellulose 2019, 1-20. [CrossRef]

9. Yuan, X.; Jayaraman, K.; Bhattacharyya, D. Plasma treatment of sisal fibres and its effects on tensile strength and interfacial bonding. J. Adhes. Sci. Technol. 2002, 16, 703-727. [CrossRef]

10. Oliveira, F.R.; Erkens, L.; Fangueiro, R.; Souto, A.P. Surface modification of banana fibers by DBD plasma treatment. Plasma Chem. Plasma Process. 2012, 32, 259-273. [CrossRef]

11. Yuan, X.; Jayaraman, K.; Bhattacharyya, D. Effects of plasma treatment in enhancing the performance of woodfibre-polypropylene composites. Compos. Part A Appl. Sci. Manuf. 2004, 35, 1363-1374. [CrossRef]

12. Wang, W.; Xian, G.; Li, H. Surface modification of ramie fibers with silanized CNTs through a simple spray-coating method. Cellulose 2019, 26, 8165-8178. [CrossRef]

13. Sarker, F.; Karim, N.; Afroj, S.; Koncherry, V.; Novoselov, K.S.; Potluri, P. High-performance graphene-based natural fiber composites. ACS Appl. Mater. Interfaces 2018, 10, 34502-34512. [CrossRef]

14. Wang, H.; Xian, G.; Li, H. Grafting of nano-TiO2 onto flax fibers and the enhancement of the mechanical properties of the flax fiber and flax fiber/epoxy composite. Compos. Part A Appl. Sci. Manuf. 2015, 76, 172-180. [CrossRef]

15. Foruzanmehr, M.; Vuillaume, P.Y.; Elkoun, S.; Robert, M. Physical and mechanical properties of PLA composites reinforced by TiO2 grafted flax fibers. Mater. Des. 2016, 106, 295-304. [CrossRef]

16. Pickering, K.L.; Li, Y.; Farrell, R.; Lay, M. Interfacial Modification of Hemp Fiber Reinforced Composites Using Fungal and Alkali Treatment. J. Biobased Mater. Bioenergy 2007, 1, 109-117.

17. Gulati, D.; Sain, M. Fungal-modification of natural fibers: A novel method of treating natural fibers for composite reinforcement. J. Polym. Environ. 2006, 14, 347-352. [CrossRef]

18. Schirp, A.; Loge, F.; Aust, S.; Swaner, P.; Turner, G.; Wolcott, M. Production and characterization of natural fiber-reinforced thermoplastic composites using wheat straw modified with the fungusPleurotus ostreatus. J. Appl. Polym. Sci. 2006, 102, 5191-5201. [CrossRef]

19. Gustavsson, M.T.; Persson, P.V.; Iversen, T.; Martinelle, M.; Hult, K.; Teeri, T.T.; Brumer, H. Modification of cellulose fiber surfaces by use of a lipase and a xyloglucan endotransglycosylase. Biomacromolecules 2005, 6, 196-203. [CrossRef]

20. George, M.; Mussone, P.G.; Alemaskin, K.; Chae, M.; Wolodko, J.; Bressler, D.C. Enzymatically treated natural fibres as reinforcing agents for biocomposite material: Mechanical, thermal, and moisture absorption characterization. J. Mater. Sci. 2016, 51, 2677-2686. [CrossRef]

21. George, M.; Mussone, P.G.; Bressler, D.C. Surface and thermal characterization of natural fibres treated with enzymes. Ind. Crops Prod. 2014, 53, 365-373. [CrossRef]

22. Francois, C.; Placet, V.; Beaugrand, J.; Pourchet, S.; Boni, G.; Champion, D.; Fontaine, S.; Plasseraud, L. Can supercritical carbon dioxide be suitable for the green pretreatment of plant fibres dedicated to composite applications? J. Mater. Sci. 2020, 55, 4671-4684. [CrossRef] 
23. Seghini, M.C.; Touchard, F.; Chocinski-Arnault, L.; Placet, V.; François, C.; Plasseraud, L.; Bracciale, M.P.; Tirillò, J.; Sarasini, F. Environmentally friendly surface modification treatment of flax fibers by supercritical carbon dioxide. Molecules 2020, 25, 438. [CrossRef] [PubMed]

24. De Prez, J.; Van Vuure, A.W.; Ivens, J.; Aerts, G.; Van de Voorde, I. Effect of enzymatic treatment of flax on fineness of fibers and mechanical performance of composites. Compos. Part A Appl. Sci. Manuf. 2019, 123, 190-199. [CrossRef]

25. De Prez, J.; Van Vuure, A.W.; Ivens, J.; Aerts, G.; Van de Voorde, I. Flax treatment with strategic enzyme combinations: Effect on chemical fiber composition and ease of fiber extraction. Biotechnol. Rep. 2019, 23, e00358. [CrossRef] [PubMed]

26. Liu, M.; Meyer, A.S.; Fernando, D.; Silva, D.A.S.; Daniel, G.; Thygesen, A. Effect of pectin and hemicellulose removal from hemp fibres on the mechanical properties of unidirectional hemp/epoxy composites. Compos. Part A Appl. Sci. Manuf. 2016, 90, 724-735. [CrossRef]

27. De Prez, J.; Van Vuure, A.W.; Ivens, J.; Aerts, G.; Van de Voorde, I. Enzymatic treatment of flax for use in composites. Biotechnol. Rep. 2018, 20, e00294. [CrossRef]

28. Stuart, T.; Liu, Q.; Hughes, M.; McCall, R.D.; Sharma, H.S.S.; Norton, A. Structural biocomposites from flax-Part I: Effect of bio-technical fibre modification on composite properties. Compos. Part A Appl. Sci. Manuf. 2006, 37, 393-404. [CrossRef]

29. Li, Y.; Pickering, K.L. Hemp fibre reinforced composites using chelator and enzyme treatments. Compos. Sci. Technol. 2008, 68, 3293-3298. [CrossRef]

30. Bledzki, A.K.; Mamun, A.A.; Jaszkiewicz, A.; Erdmann, K. Polypropylene composites with enzyme modified abaca fibre. Compos. Sci. Technol. 2010, 70, 854-860. [CrossRef]

31. Seghini, M.C.; Touchard, F.; Sarasini, F.; Chocinski-Arnault, L.; Mellier, D.; Tirillò, J. Interfacial adhesion assessment in flax/epoxy and in flax/vinylester composites by single yarn fragmentation test: Correlation with micro-CT analysis. Compos. Part A Appl. Sci. Manuf. 2018, 113, 66-75. [CrossRef]

32. Joffe, R.; Andersons, J.; Wallström, L. Interfacial shear strength of flax fiber/thermoset polymers estimated by fiber fragmentation tests. Proc. J. Mater. Sci. 2005, 40, 2721-2722. [CrossRef]

33. Kelly, A.; Tyson, W.R. Tensile properties of fibre-reinforced metals: Copper/tungsten and copper/molybdenum. J. Mech. Phys. Solids 1965, 13, 329-350. [CrossRef]

34. Boisset, C.; Petrequin, C.; Chanzy, H.; Henrissat, B.; Schulein, M. Optimized mixtures of recombinant Humicola insolens cellulases for the biodegradation of crystalline cellulose. Biotechnol. Bioeng. 2001, 72, 339-345. [CrossRef]

35. De Prez, J.; Van Vuure, A.W.; Ivens, J.; Aerts, G.; Van de Voorde, I. Flax treatment with strategic enzyme combinations: Effect on fiber fineness and mechanical properties of composites. J. Reinf. Plast. Compos. 2020, 39, 231-245. [CrossRef]

36. Abdel-Halim, E.S.; Konczewicz, W.; Zimniewska, M.; Al-Deyab, S.S.; El-Newehy, M.H. Enhancing hydrophilicity of bioscoured flax fabric by emulsification post-treatment. Carbohydr. Polym. 2010, 82, 195-201. [CrossRef]

37. Wang, Q.; Fan, X.; Gao, W.; Chen, J. Characterization of bioscoured cotton fabrics using FT-IR ATR spectroscopy and microscopy techniques. Carbohydr. Res. 2006, 341, 2170-2175. [CrossRef]

38. Haque, M.M.; Hasan, M.; Islam, M.S.; Ali, M.E. Physico-mechanical properties of chemically treated palm and coir fiber reinforced polypropylene composites. Bioresour. Technol. 2009, 100, 4903-4906. [CrossRef]

39. Abidi, N.; Manike, M. X-ray diffraction and FTIR investigations of cellulose deposition during cotton fiber development. Text. Res. J. 2018, 88, 719-730. [CrossRef]

40. Zhang, X.; Zhao, Y.; Wang, Z.; Zheng, C.; Dong, X.; Su, Z.; Sun, P.; Wang, D.; Han, C.C.; Xu, D. Morphology and mechanical behavior of isotactic polypropylene (iPP)/syndiotactic polypropylene (sPP) blends and fibers. Polymer (Guildf.) 2005, 46, 5956-5965. [CrossRef]

41. Abidi, N.; Cabrales, L.; Haigler, C.H. Changes in the cell wall and cellulose content of developing cotton fibers investigated by FTIR spectroscopy. Carbohydr. Polym. 2014, 100, 9-16. [CrossRef] [PubMed]

42. Tajvidi, M.; Takemura, A. Effect of fiber content and type, compatibilizer, and heating rate on thermogravimetric properties of natural fiber high density polyethylene composites. Polym. Compos. 2009, 30, 1226-1233. [CrossRef]

43. Van de Velde, K.; Baetens, E. Thermal and mechanical properties of flax fibres as potential composite reinforcement. Macromol. Mater. Eng. 2001, 286, 342-349. [CrossRef] 
44. Bateman, D.F.; Basham, H.G. Degradation of Plant Cell Walls and Membranes by Microbial Enzymes. In Physiological Plant Pathology; Springer: Berlin/Heidelberg, Germany, 1976; pp. 316-355.

45. Brebu, M.; Vasile, C. Thermal degradation of lignin-a review. Cellul. Chem. Technol. 2010, 44, 353-363.

46. Saleem, Z.; Rennebaum, H.; Pudel, F.; Grimm, E. Treating bast fibres with pectinase improves mechanical characteristics of reinforced thermoplastic composites. Compos. Sci. Technol. 2008, 68, 471-476. [CrossRef]

47. Gassan, J.; Bledzki, A.K. Alkali treatment of jute fibers: Relationship between structure and mechanical properties. J. Appl. Polym. Sci. 1999, 71, 623-629. [CrossRef]

48. Sawpan, M.A.; Pickering, K.L.; Fernyhough, A. Effect of various chemical treatments on the fibre structure and tensile properties of industrial hemp fibres. Compos. Part A Appl. Sci. Manuf. 2011, 42, 888-895. [CrossRef]

49. Mwaikambo, L.Y.; Ansell, M.P. Mechanical properties of alkali treated plant fibres and their potential as reinforcement materials II. Sisal fibres. J. Mater. Sci. 2006, 41, 2497-2508. [CrossRef]

50. Fraser, W.A.; Ancker, F.H.; Dibenedetto, A.T.; Elbirli, B. Evaluation of surface treatments for fibers in composite materials. Polym. Compos. 1983, 4, 238-248. [CrossRef]

51. Kim, B.W.; Nairn, J.A. Observations of fiber fracture and interfacial debonding phenomena using the fragmentation test in single fiber composites. J. Compos. Mater. 2002, 36, 1825-1858. [CrossRef]

(C) 2020 by the authors. Licensee MDPI, Basel, Switzerland. This article is an open access article distributed under the terms and conditions of the Creative Commons Attribution (CC BY) license (http://creativecommons.org/licenses/by/4.0/). 